\title{
Other infections
}

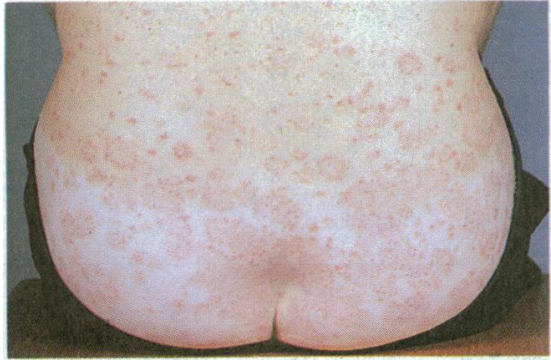

Secondary syphilis.
Infectious mononucleosis-As well as the erythematous lesions on the palate a maculopapular rash affecting the face and limbs can occur.

Cat scratch disease-A crusted nodule at the site of the scratch is associated with development of regional lymphadenopathy one to two months later. A maculopapular eruption on the face and limbs or erythema multiforme may occur.

Psittacosis and ornithosis may be associated with a rash.

Rickettsial Infections, including typhus, Rocky Mountain spotted fewer, and Rickettsial pox are all associated with rashes.

Syphilis-Although not a viral infection, the transient roseolar rash of secondary syphilis is followed by a papulosquamous eruption, which affects the trunk, limbs, and mucous membranes. The palms and soles may be affected. The diagnosis should always be considered in any rash that does not fit a recognised pattern.

Dr P K Buxton, FRCPED, FRCPC, is consultant dermatologist, Royal Infirmary, Edinburgh, and Fife Health Board.

The photographs of herpes of the lips, measles, and rubella are reproduced by kind permission of Dr A P Ball.

\section{New Drugs}

\section{Anti-infectives}

\section{ROGER FINCH}

The innovations in antibiotic treatment since this subject was last reviewed in 1983 have been dominated largely by the availability of several new and intrinsically highly active broad spectrum antibiotics. These have included additional extended range (third generation) cephalosporins such as ceftizoxime and ceftazidime, and imipenem, a novel $\beta$ lactam that is possibly the most active and has the broadest spectrum of activity of any antibiotic. In addition, a novel class of $\beta$ lactam compounds, "the monobactams," has emerged, of which aztreonam is the first to have been licensed. Another development has been the marketing of clavulanic acid, a broad spectrum inhibitor of $\beta$-lactamase enzymes, in combination with amoxycillin (Augmentin) and ticarcillin (Timentin). All these agents must be administered parenterally except amoxycillinclavulanic acid, which can also be taken orally. The other main innovation has been the development of the quinolone antibiotics, especially the fluoroquinolones such as ciprofloxacin, which are highly active broad spectrum compounds, well absorbed by mouth and also suitable for parenteral administration.

The City Hospital and University of Nottingham, Nottingham

ROGER FINCH, FRCP, MRCPATH, consultant and senior lecturer in microbial diseases

This series is edited by Professor John Feely.

\section{Cephalosporins}

ORAL AGENTS

Cefadroxil is an oral cephalosporin with a range of activity similar to that of cephalexin, cephradine, and cefaclor, though cefaclor is more active against Haemophilus influenzae. Cefadroxil has a slightly longer half life of 1.5 hours and is recommended for twice daily administration, though the justification for doses twice a day is controversial, as the other oral cephalosporins with half lives of approximately one hour are given four times daily. The antibacterial activity of the oral cephalosporins remains modest compared with other drugs, though they are widely used, especially in general practice.

Cefuroxime axetil is an oral prodrug of cefuroxime that is undergoing clinical evaluation. Its broader range of activity, including greater stability to $\beta$-lactamase inactivation, suggests that it may prove to be useful in treating infections of the lower respiratory tract and other infections where ampicillin-amoxycillin is no longer effective because of drug resistance, as is the case with $H$ influenzae.

\section{PARENTERAL CEPHALOSPORINS}

The extended spectrum cephalosporins currently marketed (cefotaxime, ceftizoxime, and ceftazidime) and those likely to become available shortly (cefotetan and ceftriaxone) present further difficulties to prescribers trying to discriminate between the various merits of this group of antibiotics. Table I summarises the main 
TABLE I-Comparison of antimicrobial activity and pharmacokinetics of extended range cephalosporins, aztreonam, and imipenem

\begin{tabular}{|c|c|c|c|c|c|c|c|c|c|}
\hline \multirow[b]{2}{*}{ Drug } & \multicolumn{9}{|c|}{ Antimicrobial activity $\left(\mathrm{MIC}_{9_{0}}\right)^{\star}$} \\
\hline & $\begin{array}{c}\text { Staphylococcus } \\
\text { aureus }\end{array}$ & $\begin{array}{c}\text { Streptococcus } \\
\text { pyogenes }\end{array}$ & $\begin{array}{c}\text { Haemophilus } \\
\text { influenzae }\end{array}$ & $\begin{array}{l}\text { Escherichia } \\
\text { coli }\end{array}$ & $\begin{array}{c}\text { Klebsiella } \\
\text { pneumoniae }\end{array}$ & $\begin{array}{l}\text { Pseudomonas } \\
\text { aeruginosa }\end{array}$ & $\begin{array}{c}\text { Bacteroides fragilis } \\
\text { spp fragilis }\end{array}$ & $\begin{array}{c}\text { Half life } \\
\text { (hours) }\end{array}$ & $\begin{array}{l}\mathrm{C}_{\max } \dagger \\
(\mathrm{mg} / \mathrm{l})\end{array}$ \\
\hline Cefotaxime & $2 \cdot 0$ & 0.05 & 0.01 & 0.6 & 0.6 & $>64$ & $\geqslant 64$ & $1 \cdot 1$ & 50 \\
\hline Ceftizoxime & $1 \cdot 0$ & 0.05 & 0.03 & 0.25 & $0 \cdot 1$ & $\geqslant 64$ & $\geqslant 64$ & 1.7 & 90 \\
\hline Latamoxef & 16 & $2 \cdot 0$ & $0 \cdot 1$ & 0.5 & 0.5 & 64 & 32 & 2 & 60 \\
\hline Cefsulodin & 6.0 & $2 \cdot 0$ & 24 & $>64$ & $>64$ & 8 & $>100$ & $1.6-1.9$ & 65 \\
\hline Ceftazidime & 12 & 0.3 & 0.06 & 0.5 & 0.5 & 4 & $>100$ & $\begin{array}{l}1.8 \\
1.8\end{array}$ & 85 \\
\hline Ceftriaxone & $6 \cdot 0$ & 0.03 & 0.01 & 1.0 & $0 \cdot 1$ & $\geqslant 64$ & $>100$ & $8 \cdot 0$ & 150 \\
\hline Cefotetan & 8 & 2 & 4 & $0 \cdot 12$ & 0.07 & $>64$ & 4 & $3 \cdot 0-4 \cdot 6$ & 140 \\
\hline Inipenem & $0 \cdot 1$ & 0.01 & $0 \cdot 1$ & 0.4 & 0.4 & $12 \cdot 5$ & $0 \cdot 2$ & 1.0 & 60 \\
\hline Aztreonam & $>100$ & $>100$ & $0 \cdot 1$ & $0 \cdot 2$ & 0.8 & 25 & $>100$ & $1 \cdot 7$ & 125 \\
\hline
\end{tabular}

${ }^{\star} \mathrm{MIC}_{90}=$ Concentration $(\mathrm{mg} / \mathrm{l})$ inhibiting $90 \%$ of strains tested.

tAfter intravenous dose of $1 \mathrm{~g}$ by bolus injection.

points of difference in activity and pharmacokinetic behaviour of these compounds.

Cefotaxime (Claforan) was the first extended spectrum cephalosporin to be introduced; it has become widely used in the treatment of serious sepsis such as intra-abdominal infection, including urinary and biliary infections and infections associated with the gut, infections of the lower respiratory tract, and, more recently, meningitis in childhood. It is highly active microbiologically and is also stable to many of the $\beta$-lactamase enzymes produced by Gram negative enteric bacteria. Despite broad spectrum activity, however, it is only modestly active against Staphylococcus aureus and Pseudomonas aeruginosa and shows little activity against anaerobic bacteria, making it an inappropriate first choice for the treatment of such infections. In keeping with all cephalosporins, it lacks activity against enterococci and Listeria monocytogenes, which is an occasional cause of meningitis.

Superinfection with enterococci and $P$ aeruginosa have made prescribing these potent cephalosporins more complicated. Resistance to the drugs has generally not been a problem, though occasional strains of enterobacter, serratia, citrobacter, and indole positive proteins have developed resistance through inducible enzymatic inactivation. Cefotaxime is metabolised to the microbiologically active desacetyl cefotaxime, which has a longer half life. Reduction of the dose is therefore necessary only in severe renal insufficiency (glomerular filtration rate $\leqslant 10 \mathrm{ml} / \mathrm{min}$ ), unlike the reductions required with other cephalosporins.

Ceftizoxime (Cefizox) is similar to cefotaxime in antibacterial activity and has a slightly longer half life but is not metabolised. Ceftazidime (Fortum) also possesses broad spectrum activity but is more active against $P$ aeruginosa and less active against $S$ taph aureus. Indications for its use are similar to those for cefotaxime, but its greater activity against $P$ aeruginosa has led to it being used in pulmonary exacerbations of cystic fibrosis and in febrile neutropenic patients who have a haematological malignancy and in whom $P$ aeruginosa may be pathogenic. Under these circumstances it is prudent to combine ceftazidime with an aminoglycoside, though success has also been reported when the drug has been used alone or in combination with another $\beta$ lactam compound. Cefsulodin (Monaspor) is a narrow spectrum cephalosporin with antipseudomonal activity, which is the primary reason for its use, though it has been used less widely than other agents.

Two other extended range agents that are active against anaerobic bacteria are latamoxef (Moxalactam) and more recently cefotetan (unlicensed at the time of writing). Like cefoxitin, cefotetan is a cephamycin, but it has a longer half life of $3 \cdot 3$ hours. Latamoxef is not active against streptococci, particularly Streptococcus pneumoniae and enterococci, but it has proved to be effective in treating a wide range of serious infections, including nonpneumococcal meningitis. It has, however, been associated with serious bleeding complications caused by the methylthiotetrazole side chain, which interferes with the synthesis of vitamin $\mathrm{K}$. There is also an effect on platelet aggregation, which contributes to this problem. Vitamin $\mathrm{K}$ should therefore be given prophylactically to patients who are at risk of vitamin $\mathrm{K}$ deficiency-namely, the

elderly, the malnourished, and those who have malignant disease; under most circumstances an alternative agent is preferred.

Cefotetan has broad spectrum activity comparable to that of latamoxef and is also active against anaerobes, including Bacteroides fragilis. It too has been extensively evaluated in a wide range of serious hospital infections, especially intra-abdominal sepsis, where it has also proved to be effective prophylactically in patients undergoing abdominal, biliary, and gynaecological surgery. Cefotetan also contains the methylthiotetrazole side chain, which suggests that caution may be necessary, though the incidence of side effects is less than that experienced with latamoxef.

Ceftriaxone differs from the above cephalosporins because of its prolonged half life of about eight hours. It has proved to be effective against a wide range of serious infections when administered either once or twice daily. It is remarkably effective against gonorrhoea, for which a single dose of $250 \mathrm{mg}$ has proved to be curative. In addition, single daily doses have been effective in treating bacterial meningitis in childhood.

\section{Monobactams}

The monobactams are a new class of antibiotic originally derived from Chromobacterium violaceum but now synthesised chemically; they are unique among the $\beta$ lactam group in that their structure consists of a single $\beta$ lactam ring (figure). Manipulation of the side chains is fairly simple and produces many compounds, including some suitable for oral use.

The first monobactam to be licensed was aztreonam, which is characterised by high activity limited to Gram negative enteric bacilli. It is administered parenterally. The main indications for its

(i) 6-Aminopenicillanic acid

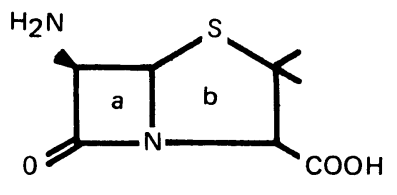

(iii) 3-Aminomonobactamic acid

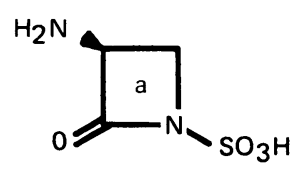

Structure of: (i) penicillins; (ii) cephalosporins; (iii) monobactams. $a=\beta$ lactam ring; $b=$ thiazolidine ring; $c=$ dihydrothiazone ring. 
use are serious infections associated with hospitals and those originating from the urinary, biliary, gastrointestinal, and female genital tracts. Of interest is the comparative lack of hypersensitivity reactions to aztreonam and in particular an appreciable lack of cross hypersensitivity to penicillins or cephalosporins. This suggests that the sensitising component of the $\beta$ lactam molecule resides in either the thiazolidine or dihydrothiazine ring attached to the $\beta$ lactam ring (figure). The lack of useful activity against Gram positive or anaerobic organisms requires aztreonam to be given with other agents when the nature of the infection remains uncertain or when a mixed infection is present.

\section{Carbapenems}

Imipenem, formerly known as $N$-formimidoyl thienamycin, is an extremely potent, broad spectrum $\beta$ lactam antibiotic. Its range of activity includes staphylococci, $P$ aeruginosa, $L$ monocytogenes, and enterococci as well as bacteria susceptible to the extended spectrum cephalosporins discussed above. Against many anaerobic pathogens, including $B$ fragilis, it is as active as metronidazole. Pseudomonas spp other than $P$ aeruginosa tend to be less susceptible, as is $S t r$ faecium and staphylococci resistant to methicillin. Unfortunately, imipenem proved to be nephrotoxic in laboratory animals, while in man, though not demonstrably nephrotoxic, urinary recovery was much reduced owing to inactivation by the renal tubular brush border enzyme dehydropeptidase I. An innovative solution to the problem has been the development of cilastatin, a reversible inhibitor of dehydropeptidase I that protects against nephrotoxicity in animals and degradation of the drug in man and has matched pharmacokinetics, thus allowing coadministration with imipenem.

Imipenem-cilastatin has proved to be effective in treating a wide range of serious infections in patients in hospital, including empirical treatment of febrile neutropenic patients who have a haematological malignancy. Side effects have included hypersensitivity reactions, common to all $\beta$ lactam antibiotics, gastrointestinal intolerance, and phlebitis. Diarrhoea or colitis due to Clostridium difficile has also occurred. In a few patients myoclonus, confusion, and, rarely, seizures have been reported. Resistance has been seen in $P$ aeruginosa during treatment and deserves further monitoring.

\section{Clavulanic acid formulations}

Clavulanic acid is an antibiotic that lacks clinically useful activity but is a potent inhibitor of many $\beta$-lactamase enzymes responsible for bacterial resistance to the $\beta$ lactam antibiotics. It is available as a formulation with amoxycillin for oral and parenteral use (Augmentin) and has recently been licensed as a combination with ticarcillin (Timentin). Amoxycillin-clavulanic acid is active against staphylococci, streptococci, anaerobic bacteria, and Gram negative enteric organisms such as Escherichia coli, proteus, klebsiella, and $H$ influenzae, including strains that produce $\beta$-lactamase and are resistant to amoxycillin. Pseudomonas spp are resistant. It has proved to be effective in treating infections of the upper and lower respiratory tract and urinary, biliary, and female genital tract. It has also been used to treat intra-abdominal sepsis as well as being effective as a surgical prophylaxis, as the formulation is active against anaerobes, including $B$ fragilis.

Ticarcillin-clavulanic acid is a formulation containing either $3 \mathrm{~g}$ or $5 \mathrm{~g}$ ticarcillin together with $200 \mathrm{mg}$ clavulanic acid. As with amoxycillin-clavulanic acid, both drugs have matched pharmacokinetics. The range of activity is greater than that of amoxycillin-clavulanic acid and includes activity against $P$ aeruginosa, though strains in which the mechanism of resistance is due to impermeability of the bacterial cell wall are not affected. In clinical use ticarcillin-clavulanic acid provides a further broad spectrum parenteral agent, and though it is active against $P$ aeruginosa, serious infections caused by this organism are best treated with ticarcillin-clavulanic acid in combination with an aminoglycoside.

\section{Quinolones}

The quinolone antibiotics are a new group of antibiotics that are rapidly increasing in number. Nalidixic acid was the forerunner of these agents and was introduced over 20 years ago, though modest activity and poor tissue pharmacokinetics have restricted its use to the treatment of infections of the urinary tract; bacterial resistance and gastrointestinal side effects are other problems associated with its use. Related compounds have included oxolinic acid and acrosoxacin (Eradacin). Oxolinic acid is also used to treat infections of the urinary tract but offers no advantage over nalidixic acid, while acrosoxacin is systemically active but limited to the oral treatment of gonorrhoea.

The quinolones are also active against a wide range of bacterial gut pathogens, and evidence suggests that they may prove to be useful in treating campylobacter, shigella, and salmonella infections, though further information is awaited.

Recent interest has focused on the fluoroquinolones, which include ciprofloxacin, enoxacin, norfloxacin, ofloxacin, and pefloxacin. These drugs are characterised by high potency and broad spectrum activity, especially against Gram negative enteric bacteria, though activity against staphylococci and streptococci is more modest (table II). Pneumococci, and in particular $B$ fragilis, are far less susceptible.

Ciprofloxacin is the most active agent in vitro and can be given both parenterally and orally. The drug achieves modest but adequate serum concentrations in many body tissues and seems to be preferentially concentrated in sites such as the lungs and prostate and also in phagocytic cells. Despite the poor in vitro activity, in clinical trials these agents have proved to be particularly effective in treating both complicated and uncomplicated infections of the urinary tract, intra-abdominal sepsis, and infections of the lower respiratory tract, including pneumococcal disease. Gonococcal infections, including those resistant to penicillin, respond very rapidly to ciprofloxacin.

Ciprofloxacin has also been used in the oral treatment of infective exacerbations of cystic fibrosis of the lung where $P$ aeruginos $a$ has been present, and response rates comparable to those achieved with parenteral treatment have been reported. Though resistance to the drug during treatment has been noted, this has not been a great

TABLE II-Comparison of antimicrobial activity and pharmacokinetics of fluoroquinolones

\begin{tabular}{|c|c|c|c|c|c|c|c|c|c|c|}
\hline \multirow[b]{2}{*}{ Drug } & \multicolumn{10}{|c|}{ Antimicrobial activity $\left(\mathrm{MIC}_{90}\right)^{\star}$} \\
\hline & $\begin{array}{l}\text { Staphylococcus } \\
\text { aureus }\end{array}$ & $\begin{array}{l}\text { Streptococcus } \\
\text { pneumoniae }\end{array}$ & $\begin{array}{l}\text { Haemophilus } \\
\text { influenzae }\end{array}$ & $\begin{array}{l}\text { Escherichia } \\
\quad \text { coli }\end{array}$ & $\begin{array}{c}\text { Klebsiella } \\
\text { pneumoniae }\end{array}$ & $\begin{array}{l}\text { Pseudomonas } \\
\text { aeruginosa }\end{array}$ & $\begin{array}{l}\text { Bacteroides fragilis } \\
\text { spp fragilis }\end{array}$ & $\begin{array}{c}\text { Half life } \\
\text { (hours) }\end{array}$ & $\begin{array}{l}\mathrm{C}_{\max } \\
(\mathrm{mg} / \mathrm{l})\end{array}$ & $\begin{array}{l}\text { Intravenous dose } \\
(\mathrm{mg})\end{array}$ \\
\hline $\begin{array}{l}\text { Ciprofloxacin } \\
\text { Enoxacin } \\
\text { Norfloxacin } \\
\text { Ofloxacin } \\
\text { Pefloxacin }\end{array}$ & $\begin{array}{l}0.5 \\
2 \\
2 \\
0 \cdot 5 \\
0.5\end{array}$ & $\begin{array}{r}2 \\
16 \\
16 \\
2 \\
8\end{array}$ & $\begin{array}{l}0.05 \\
0.25 \\
0 \cdot 12 \\
0.03 \\
0.06\end{array}$ & $\begin{array}{l}0.015 \\
0 \cdot 25 \\
0 \cdot 012 \\
0 \cdot 06 \\
0 \cdot 25\end{array}$ & $\begin{array}{l}0 \cdot 25 \\
2 \\
1 \\
1 \\
2\end{array}$ & $\begin{array}{l}1 \\
2 \\
2 \\
4 \\
2\end{array}$ & $\begin{array}{r}8 \\
12 \\
32 \\
4 \\
8\end{array}$ & $\begin{array}{r}3 \cdot 9 \\
6 \cdot 2 \\
3 \cdot 3 \\
7 \cdot 4 \\
11 \cdot 3\end{array}$ & $\begin{array}{l}2 \cdot 3 \\
3 \cdot 7 \\
1 \cdot 5 \\
5 \cdot 6 \\
5 \cdot 8\end{array}$ & $\begin{array}{l}500 \\
400 \\
400 \\
400 \\
400\end{array}$ \\
\hline
\end{tabular}

${ }^{\star} \mathrm{MIC}_{90}=$ Concentration $(\mathrm{mg} / \mathrm{l})$ inhibiting $90 \%$ of strains tested. 
problem and is more than outweighed by the advantages of oral treatment for outpatients.

Ciprofloxacin has been well tolerated, though occasional patients have developed headache, confusion, and irritability. Interactions between some quinolones and theophylline and caffeine have resulted in increased concentrations of theophylline and caffeine. In the case of theophylline, toxicity to the central nervous system, including seizures, has been observed. Ciprofloxacin should obviously be used with caution in such patients. It is also contraindicated in pregnancy and in childhood should be limited to cases where there are strong medical indications for its use, as alterations to articular cartilage have been observed in puppies.

\section{Future developments}

Many new compounds are at various stages of development; several are well advanced in their programme of clinical trials, and licensing can be expected. These include teicoplanin, additional cephalosporins, and a novel penicillin, temocillin. Teicoplanin has a similar range of activity to vancomycin and is effective in treating staphylococcal infections, including those resistant to methicillin. Infections caused by Staph epidermidis are usually susceptible, though a few resistant strains have been noted. Temocillin is unique among the penicillins in that its activity is restricted to Gram negative enteric bacilli. To date it has proved to be effective in treating a wide range of serious infections associated with intraabdominal disease and also Gram negative pneumonia.

\section{Bibliography}

Acar JF, Neu HC. Gram-negative aerobic bacterial infections: a focus on directed therapy, with special reference to aztreonam. Rev Infect Dis 1985;7(suppl 4):537-843.

This symposium reviews the development of the monobactams and in particular aztreonam. Its pharmacokinetics, safety, and low immunogenicity are reported. Experience in treating infections of the respiratory tract, those associated with obstetric and gynaecological problems, intraabdominal sepsis, infections of the urinary tract, and infections in neutropenic patients are reported.

Brown RM, Wise R, Andrews JM. Temocillin, in-vitro activity and the pharmacokinetics and tissue penetration in healthy volunteers. F Antimicrob Chemother 1982;10:295-302.

This paper reviews the comparative in vitro activity of temocillin against a broad range of clinical This paper reviews the comparative in vitro activity of temocill
isolates and also studies its pharmacokinetics in healthy men.

Cooper TJ, Ladusans E, Williams PEO, Polychronopoulos V, Gaya L, Rudd RM. A comparison of Cooper TJ, Ladusans E, Williams PEO, Polychronopoulos V, Gaya L, Rudd RM. A comparison of
oral cefuroxime axetil and oral amoxycillin in lower respiratory tract infections. $\mathcal{F}$ Antimicrob Chemother 1985;16:373-8.

Experience with cefuroxime axetil in the treatment of infection of the lower respiratory tract is reported, including comparative data with oral amoxycillin. The drug was shown to be effective and well tolerated.

Fayed SB, Sutton AM, Turner TL, McAllister TA. The prophylactic use of ticarcillin/clavulanate in the neonate. $\mathcal{F}$ Antimicrob Chemother 1987;19:113-8.

This provides data on the pharmacokinetics, safety, and clinical efficacy of ticarcillin/clavulanate in the prophylaxis of sepsis in the newborn.

File TM Jr, Tan JS, Salstrom S-J, Johnson LA, Douglas GF. Timentin versus piperacillin or moxalactam in the therapy of acute bacterial infections. Antimicrob Agents Chemother 1984;26: 310-3.

This is a randomised comparative study of ticarcillin/clavulanate, piperacillin (for respiratory and urinary tract infections), and latamoxef (for infections of soft tissue) in 116 patients. A satisfactory clinical response was seen for all agents, with few adverse reactions.

Geddes AM, Stille W. Imipenem: the first thienamycin antibiotic. Rev Infect Dis 1985;7(suppl 3): 353-536.

The antibacterial activity of imipenem, its pharmacokinetics in association with cilastatin, and an assessment of its clinical efficacy and safety in the treatment of a wide range of serious hospital infections are reported.

Harding SM, Williams PEO, Ayrton J. Pharmacology of cefuroxime as the 1-acetoxyethyl ester in volunteers. Antimicrob Agents Chemother 1984;25:78-82.

This is a pharmacokinetic study of the oral administration of cefuroxime axetil in healthy volunteers. Bowel flora were also monitored during treatment.

Maesen FPV, Davies BI, Baur C, Sumajow CA. Clinical, microbiological and pharmacokinetic studies on ofloxacin in acute purulent exacerbations of chronic respiratory disease. $f$ Antimicrob
a Chemother 1986;18:629-34.

This paper reviews the use of ofloxacin in the treatment of patients in hospital who had acute purulent exacerbations of chronic respiratory disease.

Mehtar S, Ball AP. Intravenous Augmentin in bacteraemia and severe invasive polymicrobial sepsis.

$\mathcal{f}$ Antimicrob Chemother 1985;15:765-71.

The use of parenteral Augmentin in the treatment of 17 seriously ill patients, including six who had bacteraemia, is reported.

Moellering RC Jr, Young LS. Moxalactam international symposium. Rev Infect Dis 1982;4:S489-726.

This symposium defines the in vitro activity of latamoxef and its stability to $\beta$-lactamase. It also discusses its pharmacokinetic behaviour and safety in the treatment of a wide variety of medical and discusses its pharmactions.
surgical infections.

Neu HC, Turck M, Phillips I. Ceftizoxime, a broad-spectrum $\beta$-lactamase stable cephalosporin.

f Antimicrob Chemother 1982;10(suppl C): 1-350.

This symposium provides a broad review of the comparative in vitro activity, pharmacokinetics, tissue penetration, and clinical efficacy of ceftizoxime in the treatment of infections of the respiratory tract, genitourinary tract, skeleton, and soft tissues, as well as its use in children in treating severe infections resistant to other antibiotics.

Neu HC, Phillips I. Cefotaxime. $\mathcal{F}$ Antimicrob Chemother 1984;14(suppl B):1-338.

This supplement provides a comprehensive review of the microbiological activity and pharma- cokinetic behaviour of cefotaxime in various populations and also discusses the clinical use of the drug in meningitis, haemodialysis, gonorrhoea, and infection of the urinary tract as well as the prophylactic use of cefotaxime in a broad range of surgical procedures.

Norrby SR, Jonsson M. Antibacterial activity of norfloxacin. Antimicrob Agents Chemother 1983;23: 15-8.

The comprted.

Phillips I, Ball P, Neu HC Speller DCE. Ciprofloxacin quinolones in practice. $\mathcal{F}$ Animicrob Chemother 1986;18(suppl D): 1-193.

Thother 1986;18(suppl D):1-193. This supplement provides an extensive in vitro assessment of the quinolones, including
ciprofloxacin. It also discusses their pharmacokinetics in both health and disease and provides ciprofloxacin. It also discusses their pharmacokinetics in both health and disease and provides
useful comparative and non-comparative information on the treatment of infections of the urinary and respiratory tracts, cystic fibrosis, infections of the skin and soft tissues, and gonorrhoea and also preliminary information on the treatment of infections in neutropenic patients.

Phillips I, Reeves D, Lewis D. Enoxacin in antimicrobial therapy: a look forward. 7 Antimicrob Chemother 1984;14(suppl C): 1-94.

This supplement reviews the in vitro activity, pharmacokihetics, and early clinical data of enoxacin in the treatment of infections of the respiratory tract and gonorrhoea.

Phillips I, Wise R. The role of cefadroxil in oral antibiotic therapy. $\mathcal{J}$ Antimicrob Chemother 1982;10(suppl B):1-161.

This supplement reviews the antibacterial activity, pharmacokinetics, tissue penetration, and

This supplement reviews the antibacterial activity, pharmacokinetics, tissue penetration, and
clinical experience of cefadroxil in the treatment of respiratory, urinary, ear, nose, and throat, clinical experience of cefadroxil in the
skeletal, skin, and soft tissue infections.

Phillips I, Wise R, Leigh DA. Cefotetan: a new cephamycin. I Antimicrob Chemother 1983; 11 (suppl A):1-236.

The comparative in vitro activity, stability to $\beta$-lactamase, pharmacokinetics, and preliminary clinical experience of cefotetan are reported.

Richards DM, Brogden RN. Ceftazidime. A review of its antibacterial activity, pharmacokinetic properties and therapeutic use. Drugs 1985;29:105-61.

This is a critical assessment of the in vitro activity, mode of action, pharmacokinetics, and therapeutic use of ceftazidime in infections of the respiratory and urinary tracts, septicaemia, infections of the skeleton, skin, and soft tissues, and gynaecological and intra-abdominal sepsis. It also reviews experiences of treating patients with cystic fibrosis.

Sattler FR, Weitekamp MR, Ballard JO. Potential for bleeding with the new beta-lactam antibiotics. Ann Intern Med 1986;105:924-31.

This paper reviews the problem of impaired haemostasis in patients receiving cephalosporins,
Ther $1986 ; 105: 924-31$. This paper reviews the problem of impaired haemostasis in patients
especially those agents possessing the methylthiotetrazole side chain.

Scandinavian Study Group. Imipenem/cilastatin versus gentamicin/clindamycin for treatment of serious bacterial infections. Lancet 1984;i:868-71.

This randomised study of imipenem/cilastatin compares gentamicin/clindamycin in the treatment of a wide range of serious infections. The study showed superior clinical and bacteriological efficacy and safety for imipenem/cilastatin.

Scully BE, Parry ME, Neu HC, Mandell W. Oral ciprofloxacin therapy of infections due to Pseudomonas aeruginosa. Lancet 1986;i:819-22.

This paper reviews the safety and efficacy of ciprofloxacin in the treatment of 96 episodes of $P$ aeruginosa infection caused by strains resistant to both carbenicillin and gentamicin. In patients who had cystic fibrosis the overall response was $77 \%$. Difficult infections such as complicated who had cystic fibrosis the overall response was $77 \%$. Difficult infections such
urinary tract disease, osteomyelitis, and soft tissue infections were also treated.

urinary tract disease, osteomyelitis, and soft tissue infections were also treated.
Sykes RB, Phillips I. Azthreonam, a synthetic monobactam. F Antimicrob Chemother 1981;8 Sykes RB, Phillips
(suppl E): $1-146$.

This supplement reviews the development of the monobactams and in particular the in vitro activity and pharmacokinetics of azthreonam.

Wise R, Leigh DA. Pefloxacin-a laboratory and clinical evaluation of a new quinolone. $\mathcal{f}$ Antimicrob Chemother 1986;17(suppl B): 1-115.

This supplement provides in vitro, pharmacokinetic, and therapeutic data on pefloxacin in both experimental animals and in man. It also discusses the efficacy and safety of pefloxacin in urinary tract infections and severe infections in patients in intensive care units.

\section{ANY QUESTIONS}

Should prophylactic antibiotics be given to patients recovering from near drowning in salt water, fresh water, or swimming pools? Should human normal immunoglobulin also be given to prevent hepatitis $A$ infection?

The treatment of victims of near drowning depends very much on the temperature of the water in which the immersion occurs, rather than on the type of water. The question of prophylactic antibiotics has become controversial. The choice seems to lie between awaiting the results of cultures of frequent tracheal suction specimens and prophylaxis with a broad spectrum antibiotic given intravenously in large doses. Either course would be reasonable. Orlowski favours the former, ${ }^{1}$ whereas Pearn advocates prophylaxis to avoid secondary pulmonary infection. ${ }^{2}$ Our own experience now extends to using prophylaxis in 68 patients who have definitely inhaled water (unpublished observation). There have been no problems with pulmonary or systemic infection. If a victim is known to have inhaled untreated water it is reasonable to stabilise the cardiorespiratory situation, send off a specimen of tracheal aspirate, and start prophylaxis.

It is theoretically possible to contract hepatitis A infection, but in practice development of hepatitis in the near drowned victim has not been a problem. At present immunoglobulin should be withheld unless the immersion incident occurred in water polluted with sewage or in an area where the risk of hepatitis is high.-A D sIMCOCK, consultant anaesthetist, Truro, Cornwall.

1 Orlowski JP. Drowning, near-drowning and ice water submersion. Pediatr Clin North Am 1967;30(1):75-92.

2 Pearn J. The management of near drowning. BrMed f 1985;291:1447-52. 